\title{
VIOLENCIA Y REPRESIÓN: Los discursos de María Estela Martínez de Perón \\ (1974-1976)
}

Dra. Alicia María Servetto*

Melisa Paiaro**

Resumen: Este trabajo centra su atención en los discursos y mensajes de la presidenta argentina, María Estela Martínez de Perón, entre 1974 y 1976, a los fines de revisar y analizar los componentes discursivos que sostenían la necesidad de aplicar la violencia represiva, la construcción de una determinada imagen del enemigo y sus implicancias en la instalación del Terrorismo de Estado en la etapa que precedió inmediatamente a la última dictadura militar en este país (19761983). Se busca identificar los argumentos que legitimaron los dispositivos de la violencia estatal y paraestatal como mecanismo para resolver los problemas sociales y políticos de la sociedad argentina. La hipótesis que guía este trabajo es que, en este período, se construyeron los argumentos que sustentaron el Te-

\footnotetext{
* Doctora en Historia y Magíster en Partidos Políticos por la Universidad Nacional de Córdoba (UNC). Investigadora y Directora del Centro de Estudios Avanzados de la UNC. Docente de la Maestría en Partidos Políticos y de la Cátedra de Historia Argentina Contemporánea en la Escuela de Ciencias de la Comunicación de la UNC. Directora del Programa "Política, sociedad y cultura en la historia reciente de córdoba: sujetos sociales, identidades colectivas y conflictos políticos" del Centro de Estudios Avanzados - UNC. E-mail: aliciaservetto@gmail.com ** Doctoranda en Ciencias Antropológicas en la Facultad de Filosofía y Humanidades de la Universidad Nacional de Córdoba (FFyH-UNC). Becaria de CONICET en el Centro de Estudios Avanzados-UNC. Licenciada en Historia y Docente de la Carrera de Antropología de la FFyH-UNC. Integrante del Programa "Política, sociedad y cultura en la historia reciente de córdoba: sujetos sociales, identidades colectivas y conflictos políticos" dirigido por la Dra. Alicia Servetto (CEA-UNC).E-mail: melipachus@yahoo.com.ar
}

Anos 90, Porto Alegre, v. 20, n. 38, p. 253-283, dez. 2013 
rrorismo de Estado y legitimaron la acción represiva del Estado, en sus formas institucionales y legales, y en sus formas clandestinas, ilegales y paraestatales.

Palabras clave: Violencia estatal. Terrorismo de Estado. Legislación antiterrorista. Estado de excepción.

\section{Introducción}

La apertura del proceso electoral en la Argentina de 1973 estuvo precedida por un período de diversos gobiernos, civiles y militares, que fueron incapaces de resolver el dilema de la proscripción del peronismo y el agotamiento del gobierno de la dictadura de la Revolución Argentina. ${ }^{1}$ El alto grado de movilización, sin precedentes, logrado en la campaña preelectoral estuvo íntimamente relacionado con un dato fundamental, el levantamiento de la proscripción del partido peronista. Los protagonistas principales de las elecciones fueron aquellos sectores que formaban parte del ala radicalizada del peronismo, quienes integraban lo que se dio en llamar la Tendencia Revolucionaria. ${ }^{2}$

Los resultados de las elecciones presidenciales del 11 de marzo de 1973 dieron como ganadora a la fórmula presidencial del Frente Justicialista de Liberación (FREJULI), una alianza entre el Partido Peronista - también conocido como Partido Justicialista - y varios partidos menores. ${ }^{3}$ Pero este triunfo no fue uniforme en todo el país. Mientras a nivel nacional no logró llegar al 50\% de los votos $(49,6 \%)$, en algunas provincias la alianza electoral en la que participaba el Partido Justicialista obtuvo porcentaje superiores al 60\%. Pese a que el FREJULI no obtuvo la mayoría absoluta, la magnitud de la diferencia con la primera minoría (la Unión Cívica Radical obtuvo el 21,29\%), hizo que estos renunciaran a la segunda vuelta. Además de ganar las elecciones presidenciales, contó con la mayoría absoluta en ambas Cámaras y, en casi todos los distritos provinciales, con la excepción de Capital Federal y de la provincia de Neuquén.

El 25 de mayo de 1973, la fórmula Héctor Cámpora - Vicente Solano Lima asumió la jefatura de la República. La Juventud Peronista había tenido un papel destacado en el tránsito hacia las elecciones y en el triunfo electoral, y el Presidente estaba consustan- 
ciado con la movilización social que culminaba con el retorno del peronismo al poder. En el acto estuvieron presentes el presidente chileno Salvador Allende y su par cubano, Osvaldo Dorticós, saludados calurosamente al ritmo de la consigna "Cuba, Cuba, Cuba, el pueblo te saluda". Esa misma noche una masiva manifestación frente al Penal de Devoto precipitó la liberación de todos los presos políticos, incluidos los miembros de organizaciones armadas.

El discurso del flamante presidente proclamó que había llegado "la hora de Perón" y rindió un efusivo homenaje a la "juventud maravillosa" que, "en los momentos decisivos" había sabido responder "a la violencia con la violencia y oponerse, con la decisión y el coraje de las más vibrantes epopeyas nacionales, a la pasión ciega y enfermiza de una oligarquía delirante" ${ }^{4}$ Días después, la revista de la Juventud Peronista (en adelante JP), El Descamisado ${ }^{5}$, publicó en su número 2 una nota titulada "El Tío presidente libertó a los combatientes". En ese mismo número, la JP expresaba su satisfacción por las primeras medidas tomadas por el presidente electo, remarcando, en otro titular: "Desde el vamos, Cámpora cumplió". El apoyo al presidente electo se expresaba en una serie de adjetivaciones tales como "el compañero Cámpora" o "El Tío". Mientras el primero denotaba una cualidad con quienes se compartía un "nosotros", definido en términos de "lealtad" por el cual se pasaba a formar parte de una misma comunidad de intereses, valores y conductas; la segunda expresión, refería a un vínculo más cercano y familiar. "El Tío", es, en términos de vínculos familiares, el hermano del "Padre". En este caso, el padre era el mismo Perón.

Las adjetivaciones de "El Tío" como así también la consigna repetida, una y otra vez, por la JP, "Cámpora al gobierno, Perón al poder" dejaba en claro que se trataba no sólo de una enunciación para desacreditar las intenciones de la dictadura de la Revolución Argentina al imponer restricciones a los candidatos a presidente, afectando la posible postulación del mismo Perón, ${ }^{6}$ sino también dejaba en claro que el poder no lo tenía ni lo ejercía el presidente electo. De esta forma, el flamante presidente asumía con una extrema debilidad, su autoridad quedaba sujeta y subordinada al poder de Perón, y esto, evidentemente, le restaba capacidad y margen de maniobra política. Como bien señala Luis Alberto Romero (1994), se trataba lisa 
y llanamente de una ficción de la representación política. Al respecto, resulta ilustrativa la letra de una canción coreada en los actos de la JP, titulada el "Chamamé de Cámpora", que decía entre sus estrofas:

Es un hombre leal y sincero, siempre fiel al General, Cámpora es un peronista, como no se puede más.

El nunca hizo lo que quiso sino lo que el General y el pueblo, que son lo mismo, precisaban p'ganar.

Cámpora es el delegado, del gran plan del General, el plan que es el pueblo entero, para la victoria total. ${ }^{7}$

Dos expresiones e imágenes de la letra que revelaban la ficción del proceso institucional iniciado con las elecciones de 1973: "El nunca hizo lo que quiso" y "Cámpora es el delegado". En este sentido, estos enunciados ponían de relieve la intención de convertir el mandato presidencial de Cámpora en un mero interregno. Paradójicamente, como señala César Tcach, este objetivo, alentado por Montoneros, se convirtió en un boomerang contra sus inspiradores, en virtud del posterior reacomodamiento público de Perón junto a los sectores de la derecha peronista. (TCACH, 2003, p. 44).

Efectivamente, el 20 de junio del mismo año, y luego de 18 años de proscripción, retornó al país el ex presidente, Juan Domingo Perón. ${ }^{8}$ Más de dos millones de personas fueron a esperarlo al aeropuerto internacional de Ezeiza. Se trató de la mayor movilización de masas de la historia Argentina. Ese día, que coincide con una fecha patria, recordado en el calendario nacional como el día de creación de la bandera, quedó marcado en la historia argentina por la masacre ocurrida como consecuencia del enfrentamiento interno entre los distintos sectores que conformaban el movimiento peronista y que concluyó con un elevado número de muertos y heridos. ${ }^{9}$ Los grupos de represión parapoliciales organizados desde el propio Estado (los servicios de inteligencia del Ejército, el ministerio a cargo de López Rega ${ }^{10}$ y civiles armados por comandos de extrema derecha), dispararon desde el palco y sus cercanías sobre las columnas afines a la Tendencia Revolucionaria. Estos hechos 
pueden interpretarse como la primera acción del Estado Terrorista bajo un gobierno constitucional ${ }^{11}$. Es importante señalar que, al hablar de Estado Terrorista nos referimos al agente ejecutor de un plan sistemático de eliminación de opositores políticos, que para llevarlo a cabo utiliza sus Fuerzas Armadas o el accionar de grupos paramilitares o parapoliciales contra sus ciudadanos, despojándolos de sus derechos civiles y libertades públicas, anulando las garantías constitucionales y marginando el Poder Judicial (CORRADI, 1996). El Estado Terrorista es aquél que aplica métodos de exterminio de guerra para resolver conflictos internos, en los que se califica a parte importante de la población como enemigo ajeno a la nacionalidad contra el que se ejerce todo el poder soberano (GUTIÉRREZ CONTRERAS; VILLEGAS DÍAZ, 1998, p.19 - 40).

El discurso que brindó Perón al día siguiente de su arribo - quien decidió, en pleno vuelo aterrizar, no en el aeropuerto de Ezeiza, sino en el aeródromo de Morón, para el desencanto de miles de personas movilizadas - apeló a "[...] volver al orden legal y constitucional ", enfatizando que "[...] los que ingenuamente piensan que pueden copar nuestro movimiento o tomar el poder que el pueblo ha reconquistado, se equivocan" ${ }^{12}$. A partir de ese momento, las mismas palabras fueron repetidas una y otra vez, casi obstinadamente, hasta el día en que falleció. Si alguna vez había elogiado al ala más radicalizada, eso era cosa del pasado, ahora se iniciaba una nueva etapa cuyo propósito era la armonía, la paz y la reconstrucción nacional. Con estas palabras, Perón dejó de lado los discursos ambiguos y desde entonces, comenzó a desplegar una intensa ofensiva para desplazar a los sectores más radicalizados del peronismo, inclusive al mismo presidente Héctor Cámpora. El 13 de julio de 1973, el presidente Cámpora y su vicepresidente, Vicente Solano Lima, renunciaron. La jefatura del Estado quedó a cargo del presidente de la Cámara de Diputados de la Nación, Raúl Lastiri, quien convocó nuevamente a comicios presidenciales.

Pocos meses después, se llevaron a cabo nuevas elecciones nacionales. El 23 de septiembre de 1973, triunfó la fórmula Perón-Perón con el 62\% de los votos. La dupla Juan Domingo Perón y su esposa, María Estela Martínez de Perón ${ }^{13}$, fue una suerte de operación política que permitió a los sectores más ortodoxos del pero- 
nismo y al sindicalismo más verticalista colocar a un miembro de su círculo en la primera línea de la sucesión presidencial. Mientras para algunos, esta nueva etapa era recibida como promesa de un orden político estable, otros desconfiaban de su proclividad a la conciliación. Por cierto, Perón basó su nuevo esquema de poder en el Pacto Social, pilar de la nueva política económica y social de concertación, que procuraba reorganizar las relaciones entre Estado y sociedad civil. Esta reorganización se basaba también en la propuesta de la democracia integrada, un sistema que pretendía combinar la representación política-partidaria con la participación corporativa. Se trataba de un esquema de poder en el que el peronismo radicalizado y la guerrilla urbana revolucionaria quedaban excluidos.

Desde principios de 1974, los sectores de la derecha peronista consolidaron sus posiciones dentro del gobierno, y fueron desplazando a los funcionarios relacionados con el peronismo revolucionario, entre ellos a los gobernadores provinciales que habían recibido el apoyo del peronismo de izquierda. El primer desplazado fue Antenor Gauna, de la provincia de Formosa (noviembre de 1973), le siguió el gobernador de Buenos Aires, Oscar Bidegaín (enero de 1974), y continuó en Córdoba, con la destitución del gobernador Ricardo Obregón Cano y el vicegobernador Atilio López (marzo de 1974). El punto decisivo del enfrentamiento fue la ruptura pública entre Perón y los grupos de la Juventud Peronista vinculados con la organización Montoneros durante el transcurso del acto en conmemoración del día de los Trabajadores - el $1^{\circ}$ de mayo de 1974 - , realizado en la histórica Plaza de Mayo de la ciudad de Buenos Aires. En un hecho que no tenía precedentes en la historia del peronismo, más de la mitad de los concurrentes al acto cuestionaron al mismo Perón coreando la consignas “¿Qué pasa, general, que está lleno de gorilas el gobierno popular?’. Perón modificó el tono de su discurso de unidad y pacificación nacional por una declaración de guerra. Estas palabras provocaron la retirada de las columnas de manifestantes que se identificaban con los Montoneros y la plaza quedó semivacía. El 24 de mayo, la rama juvenil fue excluida del Consejo Superior del Justicialismo.

Tras la muerte del Gral. Perón, el $1^{\circ}$ de julio de 1974, su esposa, Isabel Martínez de Perón lo sucedió en la presidencia de la Nación hasta ser depuesta por los jefes militares el 24 de marzo de 
1976. Como bien señala De Lira Rocha, María Estela Martínez de Perón o Isabel Perón (nombre artístico y político utilizado después de su casamiento) nunca fue una figura central de la historia política del país, a pesar de estar rodeada de temas polémicos y conflictivos:

ser a primera mulher vice e, posteriormente, presidenta da Argentina; estar ligada ao sempre discutido peronismo e, específicamente, a corrente dele que se aliou; a violência que ascendeu no país durante o período de sua presidência; seu conturbado gobernó e a história que o procedeu. (DE LIRA ROCHA, 2011, p. 52).

En un clima de creciente conflictividad social y violencia política, el gobierno de Isabel Martínez profundizó las alianzas políticas con los sectores de la derecha peronista, los jefes sindicales, las Fuerzas Armadas y los sectores capitalistas más concentrados. Abandonó las negociaciones y los acuerdos parlamentarios con las diferentes fuerzas políticas que había sostenido su antecesor. El proyecto del nuevo gobierno contemplaba el cumplimiento de varios objetivos para consolidar su poder: liquidar las organizaciones guerrilleras; eliminar la influencia de la izquierda peronista y marxista en los ámbitos gubernamentales (intervención a las provincias sindicadas de "montoneras", intervención a las Universidades, legislación represiva destinada a combatir la guerrilla fabril, etc.); concretar un giro en la política económica desplazando a los sectores de la burguesía, nucleada en torno a la Confederación General Económica; disciplinar a la fuerzas laborales; y solicitar colaboración a las Fuerzas Armadas para llevar adelante la represión.

Para llevar adelante este proyecto, apeló al uso de las metodologías propias del Terrorismo de Estado. La política represiva se desplegó a través de diferentes mecanismos y dispositivos que pusieron en marcha un complejo y perverso andamiaje institucional y extra institucional, legal e ilegal, para reprimir, perseguir, prohibir o eliminar a los sectores disidentes, disruptivos y opositores al gobierno. Se definieron líneas de acción que se caracterizaron por la sanción de leyes y decretos que restringían y/o prohibían una amplia gama de actividades consideradas subversivas, tales como la Ley de Seguridad 
Nacional, el decreto del Estado de Sitio, prohibiciones y sanciones a periódicos y revistas opositoras al gobierno nacional. A ello se sumaron detenciones sin juicio, torturas sistemáticas, habilitación del poder militar en el escenario político, desaparición de personas y la existencia de campos de concentración meses antes del Golpe de Estado llevado a cabo por las fuerzas militares en marzo de 1976.

Desde este ángulo de preocupaciones, este artículo procura analizar los componentes discursivos que sostenían la necesidad de aplicar la violencia represiva, la construcción de determinada imagen del enemigo, y la legitimación del Terrorismo de Estado en la etapa que precedió inmediatamente a la última dictadura militar (1976-1983). Partimos del supuesto de que la comprensión del Terrorismo de Estado instalado en la Argentina a partir del golpe militar producido el 24 de marzo de 1976 es inseparable del proceso político anterior en el que se fueron definiendo e instalando, desde el Estado, discursos legitimadores sobre el uso de la violencia en tanto instrumento de dominación política.

\section{Legalidad y poder: las leyes represivas}

Luego de la muerte del General, la lucha entre las dos vertientes del peronismo se había vuelto más cruenta. En ese marco, el gobierno de Isabel se propuso la eliminación de la guerrilla y la izquierda solicitando a las Fuerzas Armadas su colaboración directa en las acciones represivas. Esta determinación de permitir a las Fuerzas Armadas intervenir en las cuestiones de seguridad interna no había sido un invento del gobierno argentino sino, antes bien, guardaba sus fundamentos en la llamada Doctrina de la Seguridad Nacional (DSN). Difundida durante los años de la Guerra Fría, la DSN se trató de una serie de acciones de política exterior de los Estados Unidos tendientes a que las Fuerzas Armadas de los países latinoamericanos modificaran su misión para dedicarse, con exclusividad, a garantizar el orden interno, con el fin de combatir aquellas ideologías, organizaciones o movimientos que, dentro de cada país, pudieran favorecer o apoyar ideas revolucionarias, marxistas, comunistas, terroristas o subversivas. Esta Doctrina se basaba en dos postulados básicos: 
la bipolaridad y la guerra generalizada; entendiendo la división del mundo en dos grandes fuerzas opuestas: la del bien y la del mal, lo que era traducido como la guerra entre el occidente cristiano y el oriente comunista (VELÁZQUEZ RIVERA, 2002, p. 11-39).

Estos dos modelos, que se encontraban en guerra permanente en tanto enemigos antagónicos, tuvieron su correlato en América Latina en las denominadas "guerras sucias". Alli "[...] se instrumentó la tan conocida política de seguridad nacional, que remitía cualquier conflicto nacional a la confrontación global entre capitalismo y socialismo. Se aplicó en todos los países a través de los aparatos represivos del Estado, apoyados por los servicios de inteligencia norteamericanos" (CALVEIRO, 2005, p. 9). El Terrorismo de Estado fue tanto metodología de acción como instrumento represivo que permitió llevar adelante la guerra, la exclusión y el exterminio de todos los sectores, grupos o personas disruptivas que cuestionaran o se sublevaran contra el orden mundial dominante, hegemonizado por los Estados Unidos. Coincidimos con Pilar Calveiro en que,

[...] al abrigo de estas guerras se convirtió a los Estados latinoamericanos en Estados de excepción, inaugurando un derecho de facto, más allá de los bordes del derecho institucional, pero una vez más protegido por éste, bajo las figuras de estado de sitio, estado de emergencia, guerra antisubversiva y otras similares. (CALVEIRO, 2007, p. 54).

Si pensamos en los reiterados intentos de implantación de una legislación antiterrorista en la Argentina a lo largo de la historia, encontraremos que los decenios `60 - `70 y `70 - `80 han sido fructíferos en cuanto a la producción de leyes y decretos para combatir y erradicar la subversión, habilitando mecanismos de asistencia, cooperación, penalidades, formas de juzgamiento, asignaciones presupuestarias, etc. ${ }^{14}$. Al respecto, el Colectivo de Investigación y Acción Jurídica (CIAJ) sostiene que, si bien los "paquetes jurídicos antiterroristas" son sancionados para combatir a los protagonistas de las "acciones terroristas", terminan incrementando la violencia institucional y parainstitucional:

Anos 90, Porto Alegre, v. 20, n. 38, p. 253-283, dez. 2013 
Este antiterrorismo jurídico deja la puerta abierta para que las agencias policiales del Estado administren los conflictos a través de la fuerza y el terror. Los ciudadanos son desprovistos de cualquier status jurídico, convertidos en monstruos que no merecen la misericordia del Estado ni la piedad de la sociedad. Dejan de ser sujetos de derecho para convertirse en objetos de control, plausibles de un tratamiento diferenciado en el marco de una guerra preventiva de policía (PINEDO et al, 2007, p. 14).

En efecto, el corpus de la legislación represiva y antisubversiva sancionada durante los años del tercer gobierno peronista, especialmente aquellos dictados durante el gobierno de Isabel, puede entenderse dentro del marco reflexivo que propone el CIAJ. Pese a sancionarse en el contexto de un gobierno constitucional, es decir, bajo las premisas y fundamentos de un Estado de Derecho, dicha legislación recuperaba y legitimaba conceptos de la legislación represiva de los anteriores gobiernos de facto.

Julian Axat señala una serie de postulados básicos que han sido el pilar argumentativo de de este tipo de legislación anti-subversiva o anti-terrorista en nuestro país: a) Especialidad de la ley: las leyes sancionadas proponían modificaciones sobre algunas cuestiones a las que caratulaban de "especial". b) Descripción de una situación como ingobernable: se fundamentaba la ley sobre la base de un diagnóstico de la realidad como caótica, creada por la penetración/infiltración de ideologías foráneas (léase comunista, marxista, revolucionaria, etc.). c) Peligro para la Nación: se destacaba que dicha penetración creaba un clima favorable a los desbordes marxistas, colocando a la Nación en situación de peligro. d) Peligro que requiere remedios de excepción: es decir, el peligro del desborde requería de la excepción de la legalidad en defensa de los valores fundamentales, o fundantes, de la Nación. e) Transitoriedad de las medidas: la excepcionalidad se pensaba con un tiempo limitado y transitorio mientras persistiera el peligro o la amenaza. f) El instrumento era la neutralización: neutralizar todo tipo de extremismos que se opusiera a la unidad espiritual de la población. g) El fin último: era salvaguardar los valores, restituir la dignidad de las personas, la tradición nacional, la vigencia de la moral cristiana y occidental (AXAT, 2007, p. 236-237). 
Sobre la base de esta caracterización y partiendo de la idea de que la legalidad, en tanto requisito y atributo del poder, no representa la suspensión de la violencia sino, por el contrario, su consumación, nos proponemos analizar algunos ejemplos de leyes y decretos que fueron sancionados entre 1974 y 1975, en tanto permiten visualizar claramente la construcción del "enemigo subversivo" y la regularización de la "excepción". Entendemos, tal como afirma Walter Benjamín que la violencia puede ser considerada un elemento fundante no sólo del Estado sino del derecho que este configura en torno suyo. En este sentido, "[...] fundación de derecho equivale a fundación de poder, y es, por ende, un acto de manifestación inmediata de violencia" (BENJAMÍN, 1991, p. 40). Es entonces que, cuando el Estado se constituye como detentador monopólico de la violencia legítima, no la cancela como tal sino que se la apropia a los fines de preservar el status quo. Cuando otros actores políticos hacen uso de la violencia, cuestionando dicho monopolio, esta acción puede derivar en la fundación de un nuevo orden y un nuevo derecho.

Hacia mediados de 1974, la violencia había crecido de manera inusitada. Mientras la guerrilla multiplicaba sus acciones armadas, la legislación represiva iba, también, incrementando su dureza. El 28 de septiembre, el Poder Legislativo, sancionó la Ley 20.840 de Seguridad Nacional que versaba sobre las "[...] penas por actividades subversivas en todas sus manifestaciones" y estaba destinada a combatir la guerrilla. Para las autoridades nacionales, la categoría "subversivo" podía ser adjudicada a cualquier persona que actuara, "por razones ideológicas", fuera de lo establecido por las disposiciones legales imperantes. En el artículo 1, la ley establecía que la "subversión" se expresaba en aquellas personas que para lograr la finalidad de sus postulados ideológicos intentara o preconizara por cualquier medio, alterar o suprimir el orden institucional y la paz social de la Nación, por vías no establecidas por la Constitución Nacional y las disposiciones legales que organizan la vida política, económica y social de la Nación. ${ }^{15}$

En ella se instauraban diversas penalidades a las actividades y personas que promoviesen acciones sospechosas, en todas sus formas de manifestación. En ese sentido, serían punibles aquellas personas que:

Anos 90, Porto Alegre, v. 20, n. 38, p. 253-283, dez. 2013 
a) Realizaran actos de divulgación, propaganda o difusión tendientes al adoctrinamiento, proselitismo o instrucción de las conductas previstas en el artículo $\mathrm{N}^{\circ} 1$; b) Hicieran públicamente, por cualquier medio, apología del delito previsto en el artículo $\mathrm{N}^{0} 1$ o de sus autores o partícipes; c) Tuvieran en su poder, exhibieran, imprimieran, editaran, reprodujeran, distribuyeran o suministraran, por cualquier medio, material impreso o grabado, por el que se informare o propagasen hechos, comunicaciones o imágenes de las conductas previstas en el artículo $\mathrm{N}^{\circ} 1 .^{16}$

Coincidimos con De Lira Rocha en que esta ley antisubversiva, íntimamente ligada a la instauración de un orden en nombre de la Nación, donde los enemigos podrían manifestarse de varias maneras, seria "[...] a primeira institucionalização não apenas das actividades consideradas perigosas, mas também de censura de conteúdos e circulação de informações contrárias ao governo" (DE LIRA ROCHA, 2011, p. 90). Igualmente, en su artículo n.5, la ley castigaba con uno a tres años de prisión a quienes, luego de declarado ilegal un conflicto laboral por la autoridad competente, instigaran a incumplir las obligaciones impuestas. De tal manera, este artículo permitió al Ministerio de Trabajo intervenir en los conflictos laborales con amplias atribuciones para disciplinar y reprimir.

En términos generales, podemos decir que las actividades punibles eran definidas de manera confusa y ambigua, dando por sentado la existencia de un "enemigo subversivo", al que resultaba difícil identificar. Su definición era tan amplia que podía alcanzar a cualquier persona que incitara a obrar ilegalmente, pero con el agregado de que el agente que lo realizara debía perseguir "postulados ideológicos". Podemos decir, siguiendo a Julian Axat, que la construcción semántica de la categoría "subversivo" tuvo una historia jurídica enmarcada dentro de la matriz política de la época, originada a partir de la Doctrina de Seguridad Nacional, que fue generando las condiciones de aceptabilidad para la intervención del Ejército en las cuestiones internas. El subversivo siempre fue una categoría política, un adefesio político engarzado a textos jurídicos, más producto del imaginario o los sueños de exterminio del propio Estado Terrorista 
que de la realidad o de una verdadera y compleja construcción normativa. No había razón, más que política, para inventar una categoría jurídica especial llamada "subversivo". Citando a Beinutsz Szmukler:

En todo caso se trataba de sujetos que por su simple uso de la violencia política contravenían acciones prescritas en una norma penal: no hay razones para llamarlos de un modo específico o inventarles un estatuto punitivo específico por poseer una cualidad personal (AXAT, 2007, p. 241).

Siguiendo la misma línea de la Ley de Seguridad, el 6 de noviembre de 1974, cinco días después del atentado con explosivos que quitó la vida al Jefe de Policía, Alberto Villar, y a su esposa perpetrado por Montoneros, el gobierno nacional decretó el estado de sitio (Decreto 1368/74) en todo el territorio argentino. La apelación a esta normativa radicaba en

[...] que las medidas adoptadas hasta el momento por el gobierno nacional para que los elementos de la subversión depongan su actitud y se integren a la reconstrucción nacional; y que las reiteradas expresiones de repudio y recomendaciones que en igual sentido hicieron las instituciones y sectores del país - políticos, religiosos, económicos y sociales - lejos de hallar eco se agravan con las amenazas dirigidas, también ahora, contra niños en edad escolar. ${ }^{18}$

Si las anteriores medidas legislativas habían tenido la intención de persuadir a los "elementos de la subversión" para que éstos abandonasen sus prácticas y se integrasen al camino propuesto por el gobierno, este nuevo decreto no tenía la finalidad de apelar a la razón del "enemigo", puesto que éste se había convertido en la expresión "[...] de una barbarie patológica que se ha desatado como forma de un plan terrorista aleve y criminal contra la nación toda". El decreto establecía:

Que la asunción de medidas preventivas de excepción es procedente para garantizar a todas las familias su derecho

Anos 90, Porto Alegre, v. 20, n. 38, p. 253-283, dez. 2013 
natural y sagrado a vivir de acuerdo con nuestras tradicionales y arraigadas costumbres. ${ }^{19}$

Paulatinamente se imponía en la Argentina lo que Agamben llamó "permanente estado de excepción", en el que, porque todos se encuentran bajo amenaza, todos también pueden estar bajo sospecha: por lo tanto, todos constituimos un riesgo para la sociedad, aunque siempre algunos más que otros (AGAMBEN, 2004). Al respecto, Calveiro afirma que

El Estado tiene la capacidad de traspasar el derecho vigente mediante la figura del estado de excepción, que comprende la suspensión o violación de la ley amparada desde el propio derecho, para ampliar la violencia estatal en la que, a su vez, se sustenta (CALVEIRO, 2008, p. 25).

En este sentido, históricamente el estado de excepción se ha desplegado bajo las formas del estado de sitio, del estado de emergencia, entre otras figuras legales que se han utilizado a los fines de ampliar sus atribuciones. En sintonía con el planteo de Giorgio Agamben, el Estado moderno se separa del derecho a través de las medidas de excepción puesto que

La construcción de un dispositivo como la excepción jurídica permite suspender el Estado de derecho (en ciertos casos) y llevar a cabo una guerra civil legal (o ilegal) contra los individuos indeseados de la comunidad (los enemigos), a quienes se les quitará toda posibilidad de un estatuto humanitario, suspendiéndose el reconocimiento de los derechos más básicos de la persona, quedando desnudos (nuda vida), vulnerables ante un estado de emergencia o excepción que no busca (a la larga) sino su eliminación (AXAT, 2007, p. 238).

Para este autor, el estado de excepción posee dos rasgos que lo caracterizan: la confusión de los poderes (legislativo y ejecutivo) y la fuerza de la ley sin la ley. De esta manera, define un régimen de la ley en la que la norma vale pero no se aplica en tanto carece de fuerza, 
y actos que no tienen valor de ley adquieren fuerza de ésta. En este sentido, el estado de excepción se presenta como una "zona de indiferenciación", un espacio vacío de derecho o sin derecho, una zona de anomia, una "vacación jurídica". En este marco ni se cumple ni se transgrede la ley, simplemente se la inejecuta (desaplica). Es así que, al producir un espacio anómico o alógico, el estado de excepción habilita la violencia estatal sin ropaje jurídico (AGAMBEN, 2004).

Es sabido que los modernos Estados democráticos no siempre han respetado el modelo democrático puro sino que, en varias etapas de la historia de las naciones, se ha dado lugar a formas de excepción o situaciones críticas en las que esos Estados abandonan abierta o encubiertamente el imperio del derecho. No podemos dudar de que la limitación del poder haga a la esencia del Estado democrático parlamentario. Bajo el imperio de la ley, la restricción de los derechos de los ciudadanos y la vigilancia de su justa aplicación conforman los pilares de dicho modelo de Estado, basado en el principio de la seguridad jurídica de sus componentes. Esta sujeción a la ley, prevé situaciones excepcionales en que el aseguramiento de la vigencia del estado de derecho vuelve necesaria la aplicación de medidas excepcionales, contempladas por la propia ley. La excepción se naturaliza en la medida que permite conservar el orden establecido que se presume en peligro y en cada momento histórico legítima la exclusión y la prescindibilidad de aquellos que no merecen ser protegidos por la ley: son los "prescindibles-peligrosos".

Los dos ejemplos aquí citados permiten comprobar que el Estado argentino alentó y legitimó el Terrorismo de Estado, en tanto y en cuanto, en ambos casos, se trataba de supuestos que implicaban la existencia de un enemigo, o en todo caso, de enemigos que tenían muchos rostros y brazos, en cierta forma, inasibles, inciertos, desconocidos e inesperados.

Cuando el enemigo es abstracto y volátil, el poder de policía no puede tener las manos atadas, queda circunscrita su actuación a la legalidad que se desprende del Estado de derecho. Es el poder de policía el que crea derecho cuando interviene en función de la necesidad y la urgencia (RODRÍGUEZ, 2007, p. 92). 
La amenaza que el enemigo representaba, justificó el ejercicio de la coerción física transformando a todos los ciudadanos en potenciales "subversivos-peligrosos". Todos fueron puestos bajo sospecha. El miedo individual se fue transformando en terror social y el pánico se fue instalado como política de Estado. El pánico fue el instrumento de control social, en tanto permitió llevar adelante una acción de inmovilización/desmovilización y neutralización de la población. En definitiva, la figura del "subversivo" resultó funcional para imponer, bajo los cánones del terror, el disciplinamiento social y político.

\section{"Cueste lo que cueste y caiga quien caiga": Los discursos de María Estela Martínez de Perón y la legalización del aniquilamiento}

La muerte de Perón el $1^{\circ}$ de julio de 1974 aceleró el proceso de deterioro político del gobierno. El jaqueado Plan Social perdió su último sostén y la ausencia del líder llevó a un primer plano la desarticulación completa de la política de concertación.

La esposa de Perón, María Estela Martínez de Perón, Vicepresidente de la República, lo sucedió formalmente como jefa de Estado y presidenta del partido peronista. Desde entonces, el gobierno de Isabel se propuso acentuar la peronización del mismo, a partir de la alianza táctica con la ortodoxia sindical y los sectores de la derecha política. Si hasta entonces el complejo andamiaje institucional concebido por Perón fue apoyado por la principal oposición partidaria, el radicalismo, y por algunos sectores minoritarios del peronismo político y sindical, durante la gestión de María Estela Martínez de Perón, se asistió a la ruptura de cada una de alianzas construidas por el ex Presidente. La puja sectorial entre sindicalistas y empresarios, la violenta lucha interna en el interior del peronismo por conquistar espacios de poder, el predomino de los sectores más fascistoides que rodeaban a la Presidente, su progresivo aislamiento e incapacidad para gobernar, sumado a la escalada de violencia que desataron los organismos paramilitares fueron algunos de los puntos claves que marcaron el rumbo del gobierno nacional. 
En su primer discurso, la Presidenta señaló el contenido de su futuro accionar político: "Tengo dos brazos y en una mano a Perón y en la otra a Eva Perón, Perón y Eva sacrificaron sus vidas en aras y por amor al pueblo... Como alumna de Perón cumpliré fielmente su doctrina, caiga quien caiga y cueste lo que cueste" (DE RIZ, 2000, p. 160). El mensaje, con tono amenazador, dejaba asentado que la institucionalidad y el procesamiento político de los conflictos quedaban en segundo plano. "Caiga quien caiga" ponía a todos los ciudadanos bajo sospecha, desprovistos de cualquier garantía constitucional, y vulnerables frente a un Estado que comenzaba a definir con más precisiones la práctica sistemática de la fuerza y el terror. La arbitrariedad era impulsada desde la misma cúpula del Estado acompañada con el "cueste lo que cueste" que instituía, habilitaba o, mejor aún, daba la luz verde para la actuación de las fuerzas de seguridad, legitimando de esta forma, el accionar de las organizaciones parapoliciales.

Coincidiendo con De Lira Rocha, el gobierno de Isabelita "[...] aprofundou o discurso e a prática que determinavam a responsabilidade social e política pela luta antisubversiva, designando ás Forças Armadas um maior poder de ação repressora no território argentino" (DE LIRA ROCHA, 2011, p. 89). El tenor de los mensajes y discursos de la presidenta entre los años 19741976 contenía, a grandes rasgos, la misma línea argumentativa. Los discursos justificaban la necesidad de llevar adelante una política preventiva de coerción poniendo en evidencia la superposición o confusión de la violencia lícita o legítima - es decir de la violencia consentida en un estado de derecho-, con componentes y posiciones arbitrarias, autoritarias e ilícitas.

En líneas generales, los discursos de la Presidenta se iniciaban con un diagnóstico de la situación Argentina a la que caracterizaba como caótica, difícil, delicada o en estado de emergencia. Así por ejemplo, frente a los gobernadores de las provincias, a poco más de un mes de la muerte del presidente Perón, señalaba: 
La Nación apunta su proa, con decisión, hacia el futuro. Lo hace buscando salir definitivamente del cono de angustia que las pasiones incontroladas le han ido creando. Todos hemos aportado nuestra cuota de irresponsabilidad en esta situación caótica. ${ }^{20}$

Para agosto de 1974, el gobierno central ya había intervenido tres provincias, Formosa, Córdoba y Mendoza, y había obligado a renunciar al gobernador de Buenos Aires. Estas provincias estaban sindicadas como "montoneras", por lo afinidad o simpatía de sus gobernantes con el ala radicalizada el peronismo. Meses después de este discurso, por decreto presidencial, se intervinieron además las provincias de Santa Cruz y Salta. ${ }^{21}$

Las mismas palabras fueron repetidas frente al sindicalismo y al empresariado nacional. De hecho, después de la muerte de Perón, los actores sociales y empresariales arremetieron contra el pacto social y las políticas reformistas, sostenido hasta entonces por el ministro de Economía, José Ber Gelbard, uno de los empresarios referentes de la Confederación General Económica (CGE).

Sabemos que han existido y existen problemas cuya solución buscamos afanosamente día tras día. Sabemos también que todos los días superamos dificultades y avanzamos en la marcha de la Reconstrucción y la Liberación Nacional. No es posible realizar una Revolución en Paz sin pagar ninguno de los costos de la transformación. ${ }^{22}$

No tenemos todas las cosas resueltas y no nos va a ser fácil resolverlas. Ello se debe no sólo a la situación que hemos recibido en herencia, sino - esto siempre se olvida, debo seguir repitiéndolo-que estamos en una situación de emergencia. ${ }^{23}$

Efectivamente, las dificultades estructurales del programa de reformas radicaban en la debilidad de los empresarios industriales nucleados en la CGE para liderar el proceso productivo y reemplazar en esa función a los grupos capitalistas más concentrados, nacionales y transnacionales. A su vez, el Pacto Social, que preten- 
día contener por igual las demandas sectoriales de trabajadores y empresarios, provocaba en los hechos un desequilibrio: los sectores capitalistas contaban con el recurso de no invertir o de limitar sus inversiones si no acordaban con la política del gobierno. En otros términos, como plantea Ricardo Sidicaro, el Acuerdo Social agudizaba la crisis del Estado en virtud del poder que éste cedía a las corporaciones. Durante el gobierno de Isabel, la lógica de la confrontación y de la puja sectorial dejó al desnudo la pérdida de las capacidades estatales para regular los conflictos (SIDICARO, 2002).

Ahora bien, para la Presidenta, la situación de crisis por la que atravesaba el país era producto de la actividad de "enemigos" portadores de "ideologías extrañas" con respecto al auténtico sentimiento patriótico y cristiano, enemigos que pretendían imponerse mediante la violencia o la fuerza. Por ello, en sus discursos oficiales reiteraba el llamado a las organizaciones políticas, obreras y empresariales a pronunciarse contra el "terrorismo violento", la "subversión" y "el extremismo ideológico". Así en la Conferencia de gobernadores, afirmó:

Sólo me queda referirme a los ataques de los enemigos embozados que actúan unidos en dos frentes antinacionales. Todo el pueblo sabe muy bien quien es el enemigo. De nuestro lado está la Patria, con mayúscula, grande, amplia y generosa, de nuestro lado están los símbolos patrios, con su enseña azul y blanca, limpia de toda mancha infamante y con sol que ilumina el sendero de la grandeza, por encima de la pequeñez de quienes, con violencia, drogas, perjurio o prebendas, entregan al enemigo foráneo los valores que sus progenitores conquistaron con sacrificio durante una larga viada de trabajo. ${ }^{24}$

Estas definiciones de la Jefa de Estado pueden entenderse, en términos de Marina Franco, en el contexto de la matriz ideológica nacionalista. En los años setenta esta matriz estuvo relacionada con la idea de que la violencia era resultado de un enemigo ajeno y externo al "ser nacional". Esto permitió construir un "nosotros" puro y ajeno al "otro" repudiado. Probablemente, señala Franco, "[...] el efecto más potente de este discurso haya sido la generación del miedo, o de manera más vaga, de una incertidumbre atemori- 
zada y temerosa que circuló confusa y ampliamente en los intersticios sociales" (FRANCO, 2011, p. 279). Utilizado como recurso de dominación política, el miedo a la "subversión" fue instalado en la esfera pública como el problema central de la Argentina mucho antes del golpe del '76. Por cierto, los efectos psicológicos del miedo (retraimiento, ocultación, incredulidad) permiten a los detentadores del poder controlar y disciplinar a la sociedad. ${ }^{25}$

La lucha contra el enemigo debía realizarse firmemente para defender los valores occidentales, peronistas y cristianos en conjunción con las Fuerzas Armadas, baluartes y garantías del verdadero "ser nacional". Así lo expresó en la Conferencia de gobernadores en agosto de 1974:

Nuestros emblemas son sagrados y también eternos: Dios, la Patria y la Justicia Social. A Dios lo seguimos en las enseñanzas del Divino Maestro, procurando que todos los hombres amen a su prójimo como a sí mismos. Deseamos que todos los ciudadanos se unan en ese amor, porque sabemos que lo único que construye es el amor. La lucha insensata destruye los valores, los hombres y las instituciones. ${ }^{26}$

Para los argentinos, la patria debe ser una sola, con un solo cerebro y un solo corazón. Así interpreto al ser argentino y cristiano, somos una gran familia, debemos unirnos para trabajar en la grandeza de nuestra patria, y para alcanzar esta meta no es necesario recurrir a teorías extrañas a nuestra idiosincrasia, ni dejarse avasallar por los que pretenden imponerse mediante la violencia o la fuerza. ${ }^{27}$

En sintonía con las expresiones anteriores, dos meses después, volvió a apoyar el accionar de las Fuerzas Armadas en una reunión convocada por el gobierno en la que estuvieron presentes dirigentes de la Confederación General del Trabajo (CGT), empresarios de la CGE y dirigentes de varios partidos políticos. Allí las fuerzas políticas y sociales coincidieron en la necesidad de "enfrentar, combatir y erradicar" la violencia, "como punto de partida para el logro de los grandes objetivos nacionales". A su vez, la Presidenta dijo: 
Expreso mi deseo de hacer llegar la solidaridad para con el ejército Argentino que soporta en estos instantes el traidor ataque del mercenario enemigo y hacerles llegar la seguridad de que extremaremos todos los medios legales para castigar a los responsables. ${ }^{28}$

Las medidas contra el "enemigo subversivo" requerían de todas las acciones posibles, incluidas las de los tormentos físicos. Eran frecuentes las apelaciones a la figura del látigo, el mazo o el hacha. Así por ejemplo, en su discurso frente a los empresarios nacionales, destacó:

Es lamentable que los hechos criminales se destaquen en la información más que las medidas positivas de gobierno. Se quiere minimizar lo positivo, pero el gobierno tomará medidas para que de una vez por todas no se deforme la información, sino también en el exterior. ${ }^{29}$

Con términos más enfáticos, en el discurso del $1^{\circ}$ de mayo de 1975, fecha en que se conmemora el Día del Trabajador, frente a los obreros movilizados, en la histórica Plaza de Mayo, fustigó:

Dios mediante, nosotros vamos progresando paulatinamente cada vez más, pero para que ello sea realidad los necesitamos cada día trabajando más. Yo a la antipatria que se oponga, le daré con el látigo como a los fariseos en el templo. Hay un límite para la paciencia, hay un límite para la comprensión y hemos tenido demasiada paciencia y demasiada comprensión para ellos. ${ }^{30}$

En el mismo sentido, cabe destacar las expresiones de la Presidente en el mismo mes de marzo de 1976, días antes de su derrocamiento, en ocasión del congreso del Partido Justicialista. La posibilidad de un golpe de estado era anunciado por todos los medios de comunicación, locales e internacionales. 
Seguiremos adelante, porque hay una cosa que no se puede destruir en el corazón de nadie que es la fe que tenemos. Soy una mujer de inmensa fe. Dicen que la fe puede mover montañas, pero también hay un refrán español que dice "A Dios rogando y con el mazo dando". Hay algunos que se dicen peronistas y lo único que tienen de peronistas es la camiseta, peor no es cuestión de mandar a nadie a la horca porque se ahorcan solos. Perón decía que frente al movimiento hay un pozo de grandes dimensiones. Qué lástima me da ver que algunos peronistas corren rápido hacia ese pozo. En los titulares de los diarios se pone una cosa así de grande que no tiene nada que ver con el contenido, y como los diarios están un poco caros ahora... Hay otros que hacen grandes daños. Les vamos a dar con el hacha. Ya buscaremos la manera. Vamos a hacer lo que corresponde. Me tendré que convertir en la mujer del látigo si es necesario para defender la Patria. ${ }^{31}$

La presidenta solía describirse en sus discursos como una mujer "pequeña", "débil" y "pacífica", pero esas imágenes sólo eran "apariencias que engañaban”. Detrás se escondía alguien que era capaz de tomar el "látigo" o el "hacha" para imponer el orden "subvertido". Se trataba, por cierto, de una apología al accionar arbitrario, al tormento físico, a la coacción y a la represión. En esta lógica, la presidenta despojaba a los ciudadanos de sus derechos civiles y garantías constitucionales. El ejercicio de la violencia simbólica por parte de la máxima autoridad del Estado se tornaba irracional, impredecible y sin límites precisos. En otros términos, se legitimaba el accionar represivo del Estado tanto en sus formas institucionales y "legales" como en sus formas clandestinas, ilegales y paraestatales.

\section{Reflexiones finales}

La ruptura del orden constitucional fue reiteradamente anunciada por los propios políticos del gobierno, la oposición y la prensa. Por ejemplo, el mismo New York Times, en su edición del 20 de 
diciembre de 1975, es decir tres meses antes de lo que fue el golpe de estado, publicó dos notas referidas a la situación de Argentina. Una de ellas, titulada "Un hombre en la noticia", hacía referencia al Comandante General del Ejército Argentino, Teniente General Jorge Rafael Videla. En dicha nota se presentaba al General Videla como el hombre clave para pilotear la crisis argentina, poseedor de una personalidad militar distinta al común denominador de los hombres de armas de América Latina. Por otra parte, en la segunda nota referida a la Argentina, el citado matutino neoyorquino encabezaba una nota con el titular "¿Anuncio forzado para Isabel?". Allí se describía la situación del país como la más difícil crisis institucional soportada por el gobierno de la sucesora de Perón, en ocasión del alzamiento militar de un grupo de oficiales sublevados de la Fuerza Aérea. En el comentario, se reseñaba a la viuda de Perón como una mujer "con poco talento para gobernar y especialmente para proveer al país de un líder ante una nación difícilmente gobernable aún para un experimentado político como lo fue su difunto esposo" ${ }_{32}$.

No obstante los presagios de uno de los diarios más influyentes del mundo y de la política estadounidense, el gobierno de Isabel se caracterizó durante los últimos meses por un pronunciado aislamiento, quizás necesario como plantea César Tcach, para sostener la política de camarillas. Su contrapartida, en palabras del mencionado autor, fue la búsqueda deliberada del respaldo político de las fuerzas armadas con el objetivo de perpetuarse en el poder. De hecho sus seguidores, agrupados en las corrientes internas "De pie junto a Isabel" y la Juventud Peronista de la República Argentina proclamaban la reelección de la presidenta (TCACH, 1996, p. 33).

En efecto, en el acto de clausura del congreso justicialista, realizado a principios de marzo de 1976, Isabel pronunció dos discursos que tuvieron tonos diferentes y contradictorios: uno fue conciliador, llamando a la unidad nacional; el otro fue amenazante, con apelaciones a las figuras del "mazo" y la "horca". En dicha ocasión, también se escucharon entre los asistentes estribillos que acompañaban las palabras de la presidenta: "Perón, Evita y, ahora, Isabelita", "Isabel, conducción, contra toda la traición", "Soy peronista y defiendo a Isabel y si la tocan habrá guerra sin cuartel", "Vamos 
peronistas, a vencer, que la patria peronista la conduce Isabel", "Isabel vence, Isabel manda, Isabel hace lo que lo que se le da la gana".

No deja de llamar la atención que los cánticos apelan a la figura de la "guerra" para sostener el gobierno de la presidenta, que a esa altura sólo gozaba de un gran desprestigio. Este sesgo estaba en consonancia con la desvalorización de la democracia representativa y de las instituciones constitucionales como posible respuesta a la crisis política. Por cierto, habilitaba a Isabel a hacer "lo que se le da la gana".

Los años del tercer gobierno peronista se caracterizaron por un progresivo y constante deterioro de las instituciones que se demostraron incapaces de procesar los conflictos sociales y políticos. La violencia política que fue creciendo en paralelo al debilitamiento de las instituciones constitucionales. El accionar indiscriminado de los grupos de represión parapoliciales, la autorización a las Fuerzas Armadas a combatir y aniquilar a los grupos "subversivos", los secuestros de empresarios y los atentados por parte de las organizaciones guerrilleras generalizaron el clima de violencia política.

Pero fue sobre todo el propio Estado el que alentó la violencia indiscriminada, al sostener la impunidad y la arbitrariedad en la lucha contra el "enemigo subversivo". El presupuesto ideológico que sustentó esta política de estado se asentaba principalmente en la Doctrina de la Seguridad Nacional que suponía que el mundo estaba sumergido en una guerra total y permanente entre el occidente cristiano y comunismo ateo. Esta premisa suponía también que el enemigo actuaba mediante la guerra revolucionaria. El Estado de la Seguridad Nacional, en consecuencia, construyó una máquina de guerra contrarrevolucionaria.

En este sentido, fue el Estado el principal propulsor del terror que, como describe Julián Axat, se presenta en forma escalonada o en espiral: como detención legal por el mero hecho de ser considerado subversivo, o de participar en la subversión; luego como secuestro y detención ilegal; y, por último, en forma de asesinato de aquellos tildados como subversivos (o ni siquiera subversivo) - campo de concentración y desaparición forzada de personas. El terror de Estado es tríptico: es a la vez secreto, clandestino y absolutamente impune en su accionar (AXAT, 2007, p. 239). Los propósitos de la guerra desencadenada contra los individuos "indesea- 
dos" (los enemigos) justificaban la suspensión del reconocimiento de los derechos más básicos de la persona, quedando vulnerables ante un Estado de excepción que no buscaba sino su eliminación.

Estos dispositivos de funcionamiento pueden rastrearse históricamente y quizás se pueda discutir cuál es el punto de inicio, pero no puede negarse que durante el período 1973-1976 se fueron construyendo los presupuestos argumentativos y los instrumentos legales e ilegales que instituyeron el terrorismo de Estado. Es posible observar, a través de los discursos y mensajes de la presidenta María Estela Martínez de Perón la justificación y legitimación de la violencia arbitraria, indiscriminada e impune. No sólo se incrementó la legislación represiva sino que, además, se alentó y habilitó el accionar de los grupos parapoliciales que sembraron el terror social. Cuando el Estado lleva adelante una lucha contra un enemigo inasible e indefinido, caracterizado fundamentalmente por su "condición ideológica", cuando el instrumento de lucha es el miedo y el pánico, el Estado se aparta del derecho para convertirse en terrorismo de Estado.

Hacia marzo de 1976, la descomposición del régimen democrático inaugurado tres años atrás era manifiesta. Las salidas políticas alternativas eran desechadas por la misma cúpula gubernamental que tenía aspiraciones a seguir gobernando con el lanzamiento de la reelección de la Presidenta. Las organizaciones guerrilleras intensificaron su actuación a fines de $1975^{33}$, las Fuerzas Armadas manifestaron su descontento con la sublevación de las tropas de la Fuerza Aérea el 18 de diciembre de 1975, los empresarios lanzaron el primer paro del sector, con el llamado a un lock-out patronal el 16 de febrero. Los intentos de la Presidenta de promover una salida a la "uruguaya" tampoco dieron resultado. ${ }^{34}$ Cuando el 24 de marzo de 1976 las Fuerzas Armadas decidieron interrumpir el proceso institucional del país, hacia tiempo que habían asumido la iniciativa política. A principios del ${ }^{`} 76$ los militares ya tenían su propia estrategia de poder.

\section{VIOLENCE AND REPRESSION: THE SPEECHES OF MARIA ESTELA MARTINEZ DE PERÓN (1974-1976)}

Abstract: This paper focuses on the speeches and messages of the President of Argentina, Maria Estela Martinez de Peron, between 1974 and 1976, for the purpose of reviewing and analyzing the discursive components that supported

Anos 90, Porto Alegre, v. 20, n. 38, p. 253-283, dez. 2013 
the need for repressive violence, building a certain image of the enemy and its implications for the installation of state terrorism in the stage immediately preceding the last military dictatorship in this country (1976-1983). It seeks to identify the arguments that legitimized violence devices state and parastatal as a mechanism to resolve social and political problems of society in Argentina. The hypotheses of this work is that in this period were constructed arguments that supported the terrorist state and legitimized the repressive action of the State, in its institutional forms and legal forms and clandestine, illegal and parastatals. Keywords: State violence. State Terrorism. Counter-terrorism legislation. State of emergency.

\section{Notas}

${ }^{1}$ Así se autodenominó la dictadura militar Argentina impuesta a partir del derrocamiento del Presidente Arturo Illia (Unión Cívica Radical del Pueblo) mediante el golpe de Estado llevado a cabo el 28 de junio de 1966 por el Gral. Juan Carlos Onganía. La característica principal de éste régimen militar fue que no se presentó a sí mismo como "provisional", como todos los golpes militares de décadas anteriores, sino que pretendió establecerse como un nuevo régimen de gobierno de tipo permanente.

${ }^{2}$ La Tendencia Peronista estaba integrada por la Juventud Peronista, compuesta por grupos de diversa extracción e ideología. Identificada con la "patria socialista", la Tendencia incluía entre sus filas a: la Juventud Trabajadora Peronista (JTP), la Juventud Sindical Peronista, la Juventud Universitaria Peronista, la Unión de Estudiantes Secundarios, las Fuerzas Armadas Revolucionarias (FAR), los Montoneros, las Fuerzas Armadas Peronistas (FAP) y el Peronismo de Base. ${ }^{3}$ El Frente quedó finalmente integrado por los siguientes partidos: Partido Peronista, Partido Conservador Popular, el Movimiento de Integración y Desarrollo, el Partido Popular Cristiano, la rama del socialismo conducido por José Selser y siete partidos neoperonistas provinciales.

${ }^{4} \mathrm{Al}$ respecto, véase Maristella Svampa (2003).

${ }^{5}$ El Descamisado fue el órgano de difusión de la izquierda peronista, Montoneros y la Juventud Peronista. De edición semanal, fue dirigida en sus inicios por Dardo Cabo y publicada entre 1973 y 1974. Llegó a tener una importante tirada, más de 100.000 ejemplares. Se editaron un total de 47 números y contó con la colaboración de Ricardo Grassi y un conjunto de periodistas de reconocido talante, muchos de ellos luego desaparecidos. El 8 de Abril de 1974 la publicación fue censurada, por publicar una foto de un policía atacando a un manifestante en una marcha hacia la Casa Rosada.

Anos 90, Porto Alegre, v. 20, n. 38, p. 253-283, dez. 2013 
${ }^{6}$ El gobierno militar del General Alejandro Agustí Lanusse estableció como condición para las elecciones generales de 1973 que no podían ser candidatos quienes hasta el 25 de agosto de 1972 desempeñasen cargos en el Ejército nacional o en los Ejércitos provinciales. Tampoco podían serlo quienes antes de esa fecha no residieran en el país. De esta forma, Perón, exiliado en España, no podía ser candidato. ${ }^{7}$ Revista El Descamisado Año I, n. 2, Buenos Aires, 1973.

${ }^{8}$ Político y militar argentino que fuera elegido Presidente de la Nación en tres ocasiones: la primera, en las elecciones del 24 de febrero de 1946, para el período 1946 - 1952; la segunda, en las del 11 de noviembre de 1951 para el período 1952-1958, que no alcanzó a completar debido al golpe militar que lo derrocó el 21 de septiembre de 1955 y la tercera el 23 de septiembre de 1973, para el periodo 1973-1977, que no pudo completar a causa de su fallecimiento.

${ }^{9}$ Desde 1955, con el derrocamiento del presidente Juan D. Perón por el golpe militar denominado "Revolución Libertadora", se impuso la proscripción del peronismo. El partido experimentó entonces un doble efecto: no estuvo sujeto a la intervención directa de Perón - exiliado en España -, aunque, tampoco alcanzó a consolidarse ni adquirir una lógica autónoma. La vía electoral estuvo vedada hasta 1973 y el desarrollo de fuertes tendencias integracionistas al régimen por parte de algunos líderes sindicales y políticos amenazó la unidad misma del peronismo. Permeable a múltiples discursos, diversas vertientes y expresiones se fueron identificando con el peronismo. A sus apoyos tradicionales de los sectores obreros y populares, el peronismo fue sumando intelectuales y estudiantes universitarios, que al calor de las protestas sociales de los años sesenta, fueron radicalizando sus posturas ideológicas. En este contexto, la lucha armada comenzó a ser planteada por ciertos sectores como la única salida para asegurar el retorno de Perón y, el peronismo fue convertido en el instrumento para alcanzar el socialismo nacional. A grandes rasgos, podían reconocerse dos grandes tendencias, una apoyada en la vieja tradición peronista, nacionalista, verticalista y anticomunista, a la que genéricamente se la denominaba la "derecha" peronista; la otra, menos precisa, se caracterizó por pensar al peronismo como la variante nacional del socialismo. Este último grupo conformado por un conjunto heterogéneo de grupos y organizaciones fueron identificados como el ala de izquierda, o bien, como la Tendencia revolucionaria. Perón estimuló a todos los que, desde la izquierda o desde la derecha, invocaban su liderazgo y logró armar un esquema de fuerzas heterogéneas, sin temer caer en flagrantes contradicciones ideológicas.

${ }^{10}$ José López Rega fue el secretario privado de Perón y ministro de Bienestar Social de los presidentes Héctor Cámpora, Raúl Lastiri, Juan Domingo Perón y María Estela Martínez de Perón. Fue la principal figura de sector más reaccionario del peronismo y bajo su mando se creó la Alianza Anticomunista Argentina, conocida como la Triple A, organización parapolicial que practicó asesinatos

Anos 90, Porto Alegre, v. 20, n. 38, p. 253-283, dez. 2013 
selectivos para combatir la influencia de la izquierda peronista y de las organizaciones guerrilleras revolucionarias.

${ }^{11}$ Sobre la reconstrucción de los sucesos de Ezeiza, véase Verbistky, H. (1985).

${ }^{12}$ Discurso de Juan Domingo Perón, 21/06/73. Citado en Viola, 2000, p. 116.

${ }^{13}$ María Estela Martínez de Perón, conocida popularmente como Isabelita o Isabel Perón, nació en La Rioja, Argentina, el 4 de febrero de 1931. Era bailarina cuando conoció al entonces ex presidente Juan D. Perón, en Panamá. Se casaron en España en 1961. Compartió su exilio y regresó con él a la Argentina en 1973. Colaboró con la campaña del Partido Justicialista que la condujo a la Vicepresidencia de la Nación Argentina.

${ }^{14}$ Véase Axat, Julián (2007), en donde el autor enumera algunas de las leyes nacionales dictadas con el objetivo de combatir y erradicar la "subversión": 16.970/66 (Seguridad Interior); 18.234/69 (represión del comunismo); 18.670/70 (delitos de subversión); 18.953/71 (aumento penal de delitos de subversión); 19.053/71 (creación de la Cámara Federal en lo penal para juzgar delitos de subversión); 20.300/73 (partidas presupuestarias para afrontar el combate contra la subversión); 20.642/74 (suben las penas de delitos por subversión); decretos 2770, 2771, 2772/75 (intervención de las Fuerzas Armadas para aniquilar la subversión); 21.260/76 (autoriza a dar de baja a empleados públicos vinculadas a actividades subversivas); 21.264/76 (sobre represión del sabotaje); 21.269/76 (prohíbe actividades de agrupaciones políticas marxistas); 21.322/76 (se declaran ilegales y disueltas distintas organizaciones subversivas); 1.461/76 (se estableció el juzgamiento de delitos subversivos por Consejos de Guerra especiales).

${ }^{15}$ Ley 20.840 de Seguridad Nacional, Anales de la Legislación Argentina, Tomo XXXIV D, 1973, p. 3333. Citada en Paiaro (2010).

${ }^{16}$ Ley 20.840 de Seguridad Nacional, Anales de la Legislación Argentina, Tomo XXXIV D, 1973, p. 3333. Citada en Paiaro (2010).

${ }^{17}$ El estado de sitio le permitía al Poder Ejecutivo Nacional (PEN) detener sin intervención de la Justicia a sospechosos de haber cometido delitos contra el Estado. De acuerdo con el artículo 23 de la Constitución Nacional, los detenidos en esa condición podían optar por salir del país sin embargo, tras el Golpe de 1976 y hasta fines de 1977, la Junta de Comandantes suspendió esta posibilidad. El estado de sitio perduró hasta su supresión en 1983 por el Decreto $\mathrm{N}^{\circ} 2834$ (29-10-1983) (NOVARO; PALERMO, 2003).

${ }_{18}$ Anales de la Legislación Argentina, Año 1974, Tomo XXXIV D, p. 3525 (cursivas añadidas por las autoras).

19 Anales de la Legislación Argentina, Año 1974, Tomo XXXIV D, p. 3525.

${ }^{20}$ Discurso de la Presidenta en la Conferencia de Gobernadores, 27/8/74. Discursos y mensajes de la Presidenta María Estela Martinez de Perón, Secretaría de Prensa y Difusión, Presidencia de la Nación. 
${ }^{21}$ Sobre la intervención federal a las provincias durante este período, puede consultarse Servetto, 2010.

${ }^{22}$ Discurso de la Presidenta en el acto de modificación del Acta de Compromiso Nacional, 24/7/1974. Discursos y mensajes de la Presidenta María Estela Martínez de Perón, Secretaría de Prensa y Difusión, Presidencia de la Nación.

${ }^{23}$ Discurso de la Presidenta ante el empresariado nacional, 30/8/74. Discursos y mensajes de la Presidenta María Estela Martínez de Perón, Secretaría de Prensa y Difusión, Presidencia de la Nación.

${ }^{24}$ Discurso de la Presidenta en la Conferencia de Gobernadores, 27/8/74. Discursos y mensajes de la Presidenta María Estela Martinez de Perón, Secretaría de Prensa y Difusión, Presidencia de la Nación.

${ }^{25} \mathrm{Al}$ respecto, véase Servetto, 2004.

${ }^{26}$ Discurso de la Presidenta en la Conferencia de Gobernadores, 27/8/74. Discursos y mensajes de la Presidenta María Estela Martinez de Perón, Secretaría de Prensa y Difusión, Presidencia de la Nación.

${ }^{27}$ Discurso de la Presidenta en la Conferencia de Gobernadores, 27/8/74. Discursos y mensajes de la Presidenta María Estela Martínez de Perón, Secretaría de Prensa y Difusión, Presidencia de la Nación.

${ }^{28}$ Diario La Voz. del Interior, Córdoba, 9/10/74

${ }^{29}$ Discurso de la Presidenta ante el empresariado nacional, 30/8/74. Discursos y mensajes de la Presidenta María Estela Martinez de Perón, Secretaría de Prensa y Difusión, Presidencia de la Nación.

${ }^{30}$ Diario Córdoba, 2/5/75.

${ }^{31}$ Discurso de la Presidenta durante la clausura del congreso justicialista, diario La Opinión, Buenos Aires, 7/3/76.

${ }^{32}$ Diario La Opinión, Buenos Aires, 26/12/1975

${ }^{33}$ El 5/10/75 Montoneros atacó el Regimiento 29 de Infantería en la ciudad de Formosa con un saldo de 26 muertos, entre soldados y guerrilleros. El 23/12/75 el ERP intentó copar el Batallón 601 en la localidad de Monte Chingolo, provincia de Buenos Aires, con un saldo de alrededor de 50 muertos, 40 de los cuales pertenecían a la organización guerrillera.

${ }^{34}$ En enero de 1976 la Presidenta trató de obtener el apoyo de las Fuerzas Armadas sugiriendo una reforma que siguiera las líneas de una "bordaberrización" del gobierno. Esto significaba presentar una fachada civil legal, y a la vez permitir la intervención militar directa en la designación de quienes cubrirían los cargos más importantes, tal como lo había hecho en el Uruguay el presidente Bordaberry. 


\section{Referencias}

AGAMBEN, Giorgio. El Estado de excepción. In: Revista Archipiélago, n. 60, Barcelona, 2004. p. 99 - 104.

AXAT, Julián. Terrorismo o Derechos Humanos. Algunas consideraciones sobre los modelos de implantación legal de terrorismo en la Argentina. In PINEDO, Calveiro; RODRÍGUEZ, Rezses et al. Políticas de terror. Las formas del terrorismo de Estado en la globalización, Buenos Aires: AD-HOC, 2007, p. 223-277.

CALVEIRO, Pilar. Acerca de la difícil relación entre violencia y resistencia. In: LÓPEZ MAYA, Margarita; IÑIGO CARRERA, Nicolás; CALVEIRO, Pilar (eds.). Luchas contra-hegemónicas y cambios políticos recientes de América Latina, Buenos Aires: CLACSO Libros, 2008.

CALVEIRO, Pilar. La centralidad de la guerra y lo concentracionario en la reorganización global del poder. In: PINEDO, Calveiro; RODRÍGUEZ, Rezses et al. Politicas de terror. Las formas del terrorismo de Estado en la globalización, Buenos Aires: AD-HOC, 2007.

CALVEIRO, Pilar. Política y/o violencia. Una aproximación a la guerrilla de los 70. Buenos Aires: Grupo Editorial Norma, 2005.

CORRADI, Juan. El método de destrucción. El terror en la Argentina. In: QUIROGA, Hugo; TCACH, César (Comps.). A veinte años del golpe. Con memoria democrática. Rosario: Editorial Homo Sapiens, 1996.

DE LIRA ROCHA, Marina María. Uma onda de lama e sangue ameaça cubrir a república. Os discursos sobre a violência no gobernó de Isabelita Perón (junho 1975 - março 1976), Dissertação apresentada ao Programa de Pós-graduação em História, Centro de Estudos Gerais, Instituto de Ciências Humanas e Filosofía, Universidade Federal Fluminense - UFF, Río de Janeiro, 2011.

DE RIZ, Liliana. La Política en suspenso 1966/1976. Buenos Aires: Editorial Paidós, 2000.

DI TELLA, Guido. Perón-Perón. Buenos Aires: Editorial Hyspamérica, 1983.

FRANCO, Marina. Un enemigo para la nación. Orden interno, violencia y "subversión", 1973-1976. Buenos Aires: Fondo de Cultura Económica, 2011.

GUTIÉRREZ CONTRERAS, Juan Carlos; VILLEGAS DÍAZ, Myrna. Derechos Humanos y Desaparecidos en Dictaduras Militares. In: Revista América Latina Hoy, v. 20, España, 1998, p. 19-40.

NOVARO, Marcos; PALERMO, Vicente. La Dictadura militar (1976 - 1983). Buenos Aires: Paidós, 2003.

Anos 90, Porto Alegre, v. 20, n. 38, p. 253-283, dez. 2013 
PAIARO, Melisa. El poder desaparecedor en Córdoba, 1974-1976. Las formas institucionales y no institucionales del aparato represivo. Tesis de Licenciatura en Historia, Facultad de Filosofía y Humanidades, Universidad Nacional de Córdoba, 2010. RODRÍGUEZ, Esteban. Estado del miedo. El terrorismo como nuevo rudimento legitimador del Estado de malestar. In: PINEDO, Calveiro; RODRÍGUEZ, Rezses et al. Políticas de terror. Las formas del terrorismo de Estado en la globalización, Buenos Aires: AD-HOC, 2007, p. 73 - 98.

ROMERO, Luis Alberto. Breve historia de la Argentina Contemporánea, Buenos Aires: Fondo de Cultura Económica, 1994.

SERVETTO, Alicia. Córdoba en los prolegómenos de la dictadura. La política del miedo en el gobierno de Lacabanne. Revista Estudios n. 15, Centro de Estudios Avanzados de la Universidad Nacional de Córdoba, 2004.

SERVETTO, Alicia. El gobierno peronista contra las provincias "montoneras", 19731976. Buenos Aires: Editorial Siglo XXI, 2010.

TCACH, César. Heterodoxo diccionario de consignas orales. In TCACH, César (comp.); ROMERO, Luis Alberto; MORANDINI, Norma; QUIROGA, Hugo; HILB, Claudia. La politica en consignas. Memoria de los setenta, Rosario: Homo Sapiens, 2003.

TCACH, César. Partidos políticos y dictadura militar en la Argentina (19761983). In: DUTRENIT, Silvia (Coord.), Diversidad partidaria y dictaduras: Argentina, Brasily Uruguay. México: Instituto Mora, 1996.

VELÁZQUEZ RIVERA, Edgar de Jesús. Historia de la Doctrina de la Seguridad Nacional. In: Convergencia, Año 9, n. 27, México, 2002, p. 11-39.

VERBISTKY, Horacio. Ezeiza. Buenos Aires: Editorial Contrapunto, 1985.

Recebido em: 30 de maio de 2012. Aprovado em: 02 de outubro de 2012. 